\section{Eyad K. Sayhood}

Civil Engineering

Department, University of

Technology, Baghdad, Iraq

\section{Ali Sadiq Resheq}

Civil Engineering

Department, University of

Technology, Baghdad, Iraq

\section{Farah L. Raoof}

Civil Engineering

Department, University of

Technology, Baghdad, Iraq

Received on: 22/07/2018

Accepted on: 24/01/2019

Published online: 25/06/2019

Egypt, Cairo, 24-28 November 2018

\title{
Behavior of Recycled Aggregate Fibrous Reinforced Beams Under Flexural and Shear Loading
}

\begin{abstract}
The use of recycled concrete aggregates (RCA) to replace part or all of the natural coarse aggregates (NCA) in the production of concrete has been on the increase. Such use helps in the protection of the natural resources and in the reduction in the use of landfills. The experimental work consists of casting and testing ten rectangular simply supported reinforced concrete beams of dimensions $(1500 * 150 * 240) \mathrm{mm}$ with concentric point load at mid span as well as tests for control specimens to determine the mechanical properties of the concert. Five beams of these ten beams were designed to fail in flexure and other five beams were designed to fail in shear. Two beams were considering as a reference beams using normal aggregate (NCA) and two beams were considering as a reference beams using recycled aggregate (RCA. The other six beams were cast using recycled concrete aggregates (RCA) with steel fiber in three different volumetric ratio (vf).The present investigation contains three main variables: Coarse aggregate (normal and recycled). Transverse reinforcement (with stirrups spacing $50 \mathrm{~mm}$ for flexure failure mode and without stirrups for shear failure mode). Steel fiber (vf) $=(0.5) \%$, (1) $\%$ and $(1.5) \%$. In addition, constant longitudinal reinforcement ratio 0.012 . Experimental results have generally showed that ultimate loads $(\mathrm{Pu})$ of beams made with RA are approximately close to the results of beams made with NA but with decrease of values (14\% and $21 \%)$ for flexural and shear behavior respectively. The ultimate load of fibrous concrete beams is greater than beams without steel fiber by $(33 \%-50 \%)$ for shear behavior and $(21 \%-35 \%)$ for flexure behavior.
\end{abstract}

Keywords- Normal aggregate concrete (NAC), Recycled aggregate concrete (RAC), Normal coarse aggregate (NCA) Recycled coarse aggregate (RCA), volumetric ratios of steel fiber (vf).

How to cite this article: E.K. Sayhood, A.S. Resheq and F.L. Raoof, "Behavior of Recycled Aggregate Fibrous Reinforced Beams Under Flexural and Shear Loading," Engineering and Technology Journal, Vol. 37, Part C, No. 3, pp. 338-344, 2019.

\section{Introduction}

Concrete is the single most widely used material in the world. In all construction of buildings work such as infrastructures, defense, low and high buildings, and sustainability of the construction industry [1].

At present, the concrete industry consumes almost 12 billion tons of natural aggregates yearly. Such a large consumption can cause extensive destruction of the environment. Utilization of recycled aggregates can reduce the environmental impact and preserve the natural resources used in concrete applications [2].

Reuse demolition waste is one of the primary objectives of sustainable construction. In summary, the benefits of using round aggregates are as follows:

\section{Environmental Significance}

Recently, the interest of the environmental impacts of construction and sustainable development, recycled concrete is an effective resource to compensate for the exhaustion of natural resources. It is an inactive substance, making it an ideal way to recycle building debris. They are energy-efficient, continue to gain strength over time, and can be recycled old reinforced concrete and used as aggregates in new concrete.

\section{Economic Factors}

Concrete recycling is an attractive option for government agencies and contractors alike. Most municipalities impose strict environmental controls on opening new-pooled sources. In many areas, the cost of starting new quarries is increased. For demolition contractors, the area of landfills is limited and can be remote, especially 
in urban areas. Thus, disposal of old concrete and construction is costly. Dump charges are also likely to increase as construction debris increases and fewer landfill sites become accessible. Moreover, the cost and transportation distances of traditional aggregates can continue to increase with the scarcity of resources.

\section{Save Energy}

According to the Kajima Institute for Technical Research (2002), Kajima is developing a method to recycle the crushed concrete used in construction, known as the on-site recycling system. Recycling, manufacturing, and use are carried out at the same location. This can provide energy to transport materials to recycling plants.

Although there are many advantages to using recycled aggregates. However, there are still some defects [3] like:

1) High absorption of water.

2) High drying shrinkage and creep.

3) Drop in strength.

It is generally realized that there is a critical potential purpose behind decimated flotsam and debris reusing, to utilize in esteem added utilizations to get the most out of cost-effective and natural benefits. Because of that, reusing designing in many country around the world, convert low-esteem wastes into subordinate materials, for example, a fluctuation of total fines (dust), total levels, and street materials, and these materials are regularly utilized in the street make, second rate creation of cement, refill for holding dividers, brickwork, seepage, and square work for minimal effort outline [4]. Asian nations ought to truly consider RCA applications because of the developing of solid release for consistently [5]. Hong Kong, Japan, and China have transformed into pioneer areas in Asia, which effectively coordinated investigations on RCA asks for in building industry [6]. The crushers, which are utilized as of late for the reusing of rubble, were not planned or grown particularly for a reason. The greater part of crushers began from coal and preparing from regular stone pulverizing plants. Crushers were changed to adjust the level of size decrease, and the molecule estimate appropriation. A cone crusher and jaw crusher and Impact crusher

*Jaw crusher included of two plants settled at one plate, stays fix while the other plate wavers forward and backward with respect to the settled plate.

*Impact crusher: utilize overwhelming steel blow bars" mounted on an even or vertical rotor to more than once affect solid sections and heave them against steel iron blocks or "break plates" in the crusher lodging. The rotor keeps on tossing particles that are bigger than the coveted best estimate.
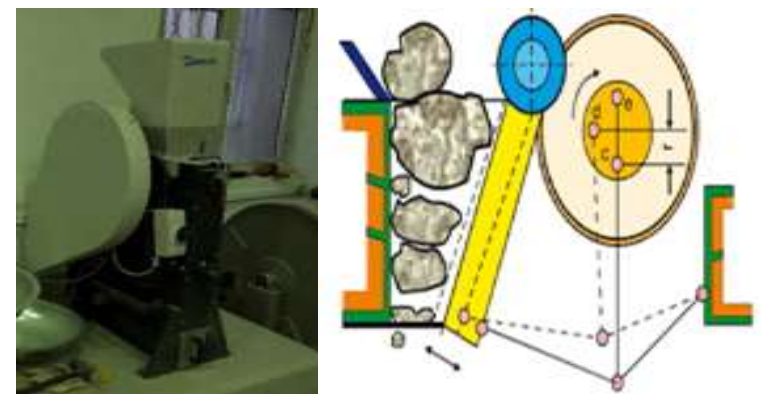

Figure 1: Sketch of crushing equipment machine

* cone crusher: use an eccentric rotor cone to trap and crush concrete crumbs

The major objective of present work that investigated the flexural and shear behavior of reinforced concrete beams that use recycled aggregates (RA) from waste concrete as a full replacement for natural aggregates (NA) with the maximum size $(19 \mathrm{~mm})$ and with an addition of steel fibers in three different percentage.

\section{Materials Used and Mix Design}

In this work, the materials used for casting concrete beams are :

1. Local produced Ordinary Portland cement.

2. Fine aggregates that fineness modulus and specific of gravity are $(2.55,2.54)$ respectively

3. Coarse aggregates with maximum size (19) $\mathrm{mm}$, specific of gravity $(2.63) \mathrm{mm}$ and $(0.54 \%)$ absorption.

4. Recycled aggregate with a specific gravity (2.56) $\mathrm{mm}$ and absorption (4\%).

5. Potable water.

6. Deformed steel reinforcing bars ( $\phi 16$ and $\phi 8)$ $\mathrm{mm}$.

7. Super plasticizers (glinume51).

8. Micro steel fiber that the aspect ratio (75) and tensile strength $2850 \mathrm{MPa}$.In the program of testing. All materials were tested and complied with international or Iraqi equivalent standard.

The Characteristic compressive strength of concrete beams is $30 \mathrm{MPa}$. The dimensions of beams were $(1500 * 150 * 240) \mathrm{mm}$, and mix proportion of $(1: 1.76: 2.64)$ with a water/cement ratio of 0.45 , as shown in Table 1 .

Table1: The main details of the mixes used throughout this work 


\begin{tabular}{lllllll}
\hline \hline Mixes & $\begin{array}{l}\text { Cement } \\
\mathbf{k g} / \mathbf{m} 3\end{array}$ & $\begin{array}{l}\text { NFA } \\
\mathbf{k g} / \mathbf{m 3}\end{array}$ & $\begin{array}{l}\text { NCA } \\
\mathbf{k g} / \mathbf{m 3}\end{array}$ & $\begin{array}{l}\text { RCA } \\
\mathbf{k g} / \mathbf{m 3}\end{array}$ & $\begin{array}{l}\text { Water } \\
\mathbf{l} / \mathbf{m 3}\end{array}$ & $\mathbf{S P} \mathbf{~ / / m 3}$ \\
\hline NC & 400 & 704 & 1056 & - & 180 & - \\
RC 0 & 400 & 704 & - & 1056 & 180 & 0.75 \\
RC0.5 & 400 & 704 & - & 1056 & 180 & 0.88 \\
RC1 & 400 & 704 & - & 1056 & 180 & 1 \\
RC1.5 & 400 & 704 & - & 1056 & 180 & 1.2 \\
\hline
\end{tabular}

In this study, the workability of concrete is reduced for two main reasons:

First, the needle shape of the steel fiber affects the internal structure of the concrete, where the new concrete becomes stiffer and resistant in fresh condition. The second reason is the rough surface and the angular shape of the recycled aggregate. Therefore, superplasticizers were used to control the workability for all mixes except the control one.

\section{Experimental Work}

Ten concrete beams of dimension $(1500 * 150 * 240)$ were tested in this work under increment load up to failure, moreover, to recording the deflection at mid-span, cracking load and maximum load. Five of them were designed to fail in flexure in Figure (2-a), the other beams were designed to fail in shear (without stirrups), Figure (2-b). The ten beams were divided into four groups, as shown in Table

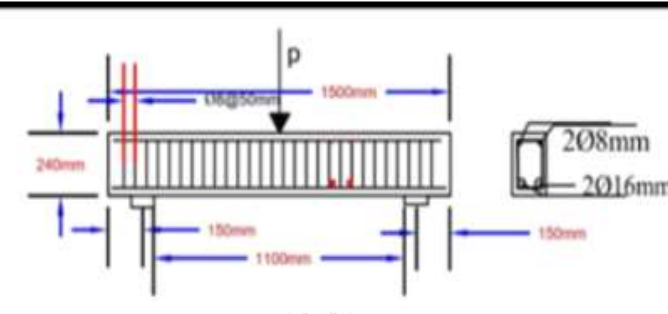

(a)

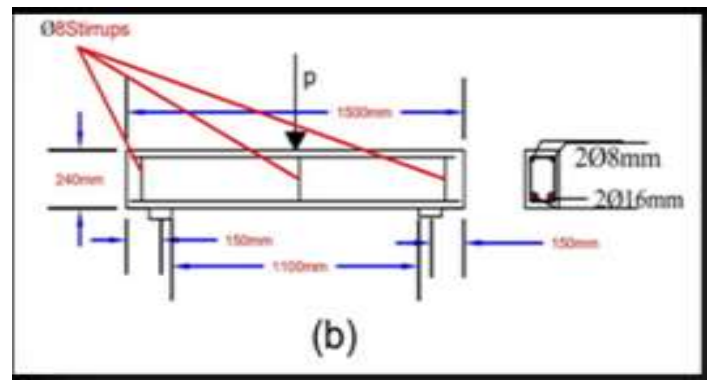

2.

Figure 2: Beams reinforcement details (a- Flexural failure mode, b-Shear failure mode)
Table 2: Experimental program (Beams details)

\begin{tabular}{clll}
\hline \hline Group & Beam designation & Vf & $\begin{array}{l}\text { Design } \\
\text { failure mode }\end{array}$ \\
\hline G1 & NAC fC & $0 \%$ & Flexure \\
& NAC shC & $0 \%$ & Shear \\
G2 & RAC fC & $0 \%$ & Flexure \\
& RAC shC & $0 \%$ & Shear \\
G3 & RAC f 0.5 & $0.5 \%$ & Flexure \\
& RAC f 1 & $1 \%$ & Flexure \\
& RAC f 1.5 & $1.5 \%$ & Flexure \\
G4 & RAC f 0.5 & $0.5 \%$ & Shear \\
& RAC sh 1 & $1 \%$ & Shear \\
& RAC f 1.5 & $1.5 \%$ & Shear \\
\hline
\end{tabular}

\section{Experimental Results and Discussion}

\section{Compressive quality}

The compressive strength of concrete is the most common measure for judging not only the ability of the concrete to withstand the load, but also the quality of the hardened concrete in structural design. This results obtained from compressive strength, the test was performed by ASTM C 39/C 39M-03 (Table 3).

Where:

NA Control specimen of the mix (1) for normal aggregate and without steel fiber.

RA0 Control Specimen of the mix (2) for recycled aggregate and without steel fiber.

RA 0.5Concrete Specimen for recycled aggregate and with $(0.5 \%)$ of steel fiber.

RA 1Concrete Specimen for recycled aggregate and with $(1 \%)$ of steel fiber.

RA 1.5 Concrete Specimen for recycled aggregate and with (1.5\%) of steel fiber.

Table 3: Test results for compressive strength

\begin{tabular}{lrrr}
\hline \hline MIX & \multicolumn{1}{l}{ fc'(MPa) } & fcu (MPa) & \multicolumn{2}{l}{ fc' / fcu } \\
\hline NAC & 29.5 & 37.30 & 0.79 \\
RAC 0 & 23.7 & 29.60 & 0.8 \\
RAC 0.5 & 28.1 & 34.70 & 0.81 \\
RAC 1 & 30.2 & 37.30 & 0.81 \\
RAC 1.5 & 31.3 & 40 & 0.78 \\
\hline
\end{tabular}




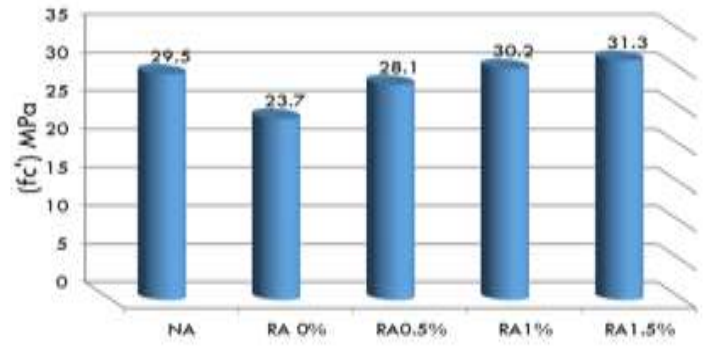

Figure 3: Effect of using recycled aggregates with steel fiber on the compressive strength of concrete

\section{II.Splitting tensile strength (ft)}

It is one of the important property of concrete in a hardened stage which that indicated to cracking of the concrete, often refers to tension stress, the test was performed according to

ASTM C496/C496M- 11.

Table 4 present Splitting tensile tests

(ACI 363R-1992), $\mathrm{ft}=0.59\left(\mathrm{fc}^{\prime}\right)^{0.55}$

(ACI 318M-2014), $\quad \mathrm{ft}=0.56 \sqrt{ } \mathrm{fc}^{\prime}$

Table 4: Test results for splitting tensile strength and predicated results

\begin{tabular}{lll}
\hline \hline Mix & $\begin{array}{l}\text { ft (experimental), } \\
\text { MPa }\end{array}$ & $\begin{array}{l}\text { ft (predicted), } \\
\text { MPa } \\
\text { ACI 318M-2014 }\end{array}$ \\
\hline NAC & 3.25 & 3.04 \\
RAC 0 & 2.70 & 2.72 \\
RAC 0.5 & 3.35 & 3.00 \\
RAC 1 & 3.60 & 3.10 \\
RAC 1.5 & 3.72 & 3.13 \\
\hline
\end{tabular}

(ft) MPa

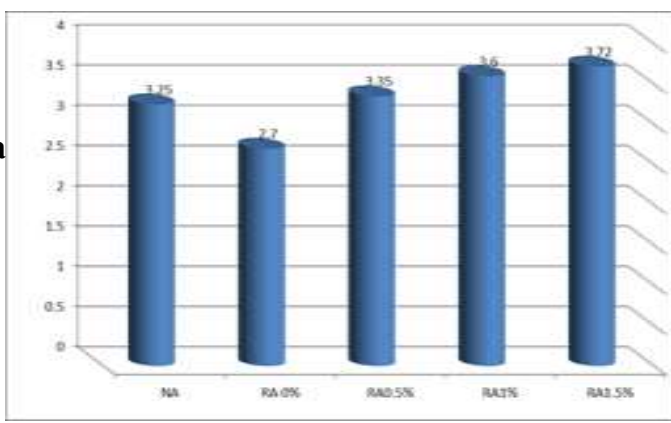

Figure 4: Effect of using recycled aggregates with steel fiber on the splitting tensile strength of concrete

\section{III.Flexural strength (fr)}

Flexural strength is known as bend strength or modulus of rupture in concrete that the ultimate tensile stress tested, can be calculated from the form used for elastic material

$\mathrm{fr}=0.62 \sqrt{ } \mathrm{fc}^{\prime}$

The test was performed according to By (ACI 318M-2014):

The experimental results of flexural strength were compared with predicted results as shown in table 5 Where: $\mathrm{fc}^{\prime}$ and fr in MPa.
Table 5: Test results for flexural strength and predicated results

\begin{tabular}{lll}
\hline \hline Mix & $\begin{array}{l}\text { fr (experimental) } \\
\text { MPa }\end{array}$ & $\begin{array}{l}\text { fr (predicted) } \\
\text { MPa } \\
\text { ACI 318M-2014 }\end{array}$ \\
\hline NAC & 3.56 & 3.36 \\
RAC 0 & 2.9 & 3.01 \\
RAC 0.5 & 3.60 & 3.30 \\
RAC 1 & 3.85 & 3.40 \\
RAC 1.5 & 3.95 & 3.47 \\
\hline
\end{tabular}

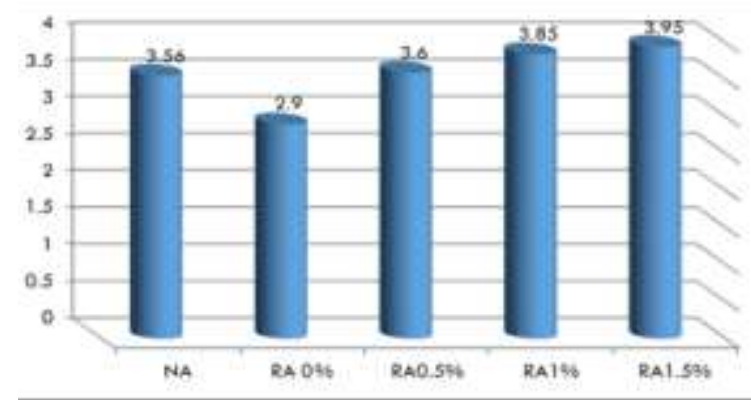

Figure 5: Effect of using recycled aggregates with steel fiber on the flexural strength of concrete

\section{Modulus of Elasticity (Ec)}

Elastic modulus one of the important property of concrete. It was determined according to the ASTM C469-02.It can be obtained by carrying a compressive test on concrete cylinders

Table 6 and Figure 6 illustrate values of elastic modulus for various strength and the predicted values using the following equations:

$(\mathrm{ACI} 318 \mathrm{M}-2014), \quad \mathrm{Ec}=4700 \sqrt{ } f^{\prime} \mathrm{c}$

Table 6: Test results for elastic modulus

\begin{tabular}{|c|c|c|}
\hline MIX & $\begin{array}{l}E C \\
\text { (experimental), } \\
M P a\end{array}$ & $\begin{array}{l}E C(\text { predicted }), \\
M P a A C I \\
318 M-2014\end{array}$ \\
\hline NAC & 26100 & 25527.5 \\
\hline RAC 0 & 23582 & 22880.8 \\
\hline RAC 0.5 & 27064 & 24914.4 \\
\hline RAC 1 & 28020 & 25828.6 \\
\hline RAC 1.5 & 28842 & 26294.8 \\
\hline
\end{tabular}

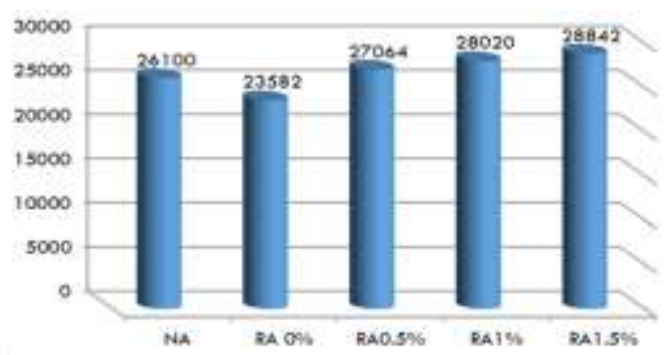

Figure 6: Effect of using recycled aggregates with mixes 


\section{V.Cracking and Ultimate load (Pcr and Pu)}

Cracking load is known as the load at which the first notice cracks on the surfaces of the beam is observed. The results of the cracking load and ultimate load show in Table 7. It is obviously that the value of cracking load and maximum load increase as $\mathrm{Vf}$ increases.Cracking load to the ultimate load ratio $(\mathrm{Pcr} / \mathrm{Pu})$ was in general between.\% $(0 \wedge-r \uparrow)$

Table 7: Tested beams results for cracking and ultimate loads

\begin{tabular}{llll}
\hline \hline Beam & $\boldsymbol{P c r}(\boldsymbol{k N})$ & $\boldsymbol{P u}(\boldsymbol{k N})$ & $\boldsymbol{P c r} / \boldsymbol{P u}(\%)$ \\
\hline NAC fC & 70 & 162.5 & 43.07 \\
RAC fC & 56 & 140.5 & 39.14 \\
RAC f 0.5 & 90 & 170 & 52.94 \\
RAC f 1 & 95 & 185 & 51.35 \\
RAC f 1.5 & 110 & 190 & 57.89 \\
NAC shC & 40 & 105 & 38.09 \\
RAC shC & 30 & 82.5 & 36.36 \\
RAC sh0.5 & 50 & 110 & 45.5 \\
RAC sh 1 & 70 & 145 & 48.27 \\
RAC sh 1.5 & 80 & 165 & 48.48 \\
\hline
\end{tabular}

The values of cracking load for the control beam with natural aggregate greater than the value of control beam with recycled aggregate when the other parameters are kept fixed. It was already interactive and exposed to tensile stress thus the bonding with the remain concrete component would be little then the cracking load (Pcr) would be lower. But when steel fiber with different percentage $(0.5,1$ and $1.5 \%)$ was added, observed improvement of concrete in cracking load. Percentage of these increments is about (60.7-94) $\%$ for flexural behavior and (66-166) \% for shear behavior. For the same reason, the decrease in the ultimate load due to the addition of recycled aggregate will be compensated when the Steel fiber in different percentage was added by increase about (21-35)\% for flexural behavior and about (33-100)\% for shear behavior.

\section{Load Deflection Behavior}

Deflection in this work was measured at mid-span of all tested beams. Table 8 shows the maximum deflections of the beam with the ultimate load. Fig.7 shows the load-deflection curves of all beams; and Fig. 8 shows failure mode and Crack patterns for some tested beams.

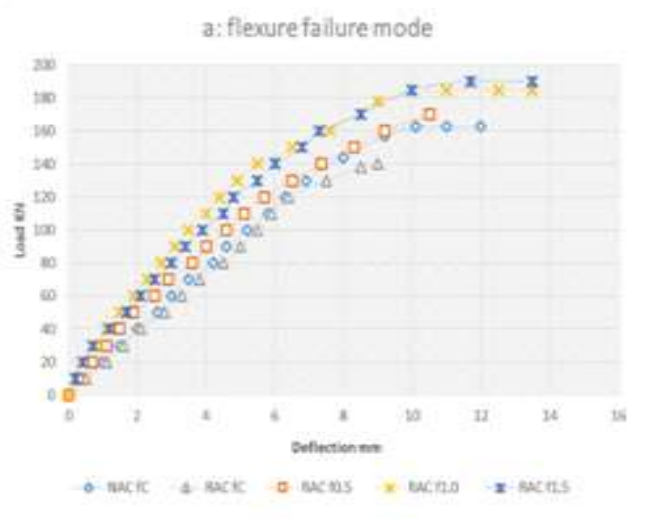

Figure 7-a: Load- deflection relationships Beams failed in flexure

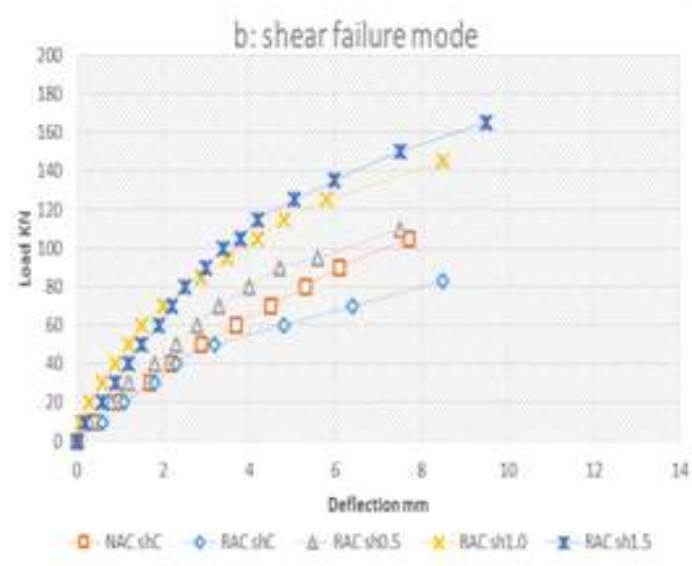

Figure 7-b: Load- deflection relationships Beams failed in shear

Table 8: Maximum deflection in center of beams

\begin{tabular}{lll}
\hline \hline Beam & $\begin{array}{l}\text { Ultimate Load } \\
(\mathbf{k N})\end{array}$ & $\begin{array}{l}\text { Max. Deflection } \\
(\mathbf{m m})\end{array}$ \\
\hline NAC fC & 162.5 & 10.1 \\
RAC fC & 140.5 & 9 \\
RAC f 0.5 & 170 & 10.5 \\
RAC f 1 & 185 & 11.7 \\
RAC f 1.5 & 190 & 11.7 \\
NAC shC & 105 & 7.7 \\
RAC shC & 82.5 & 8.5 \\
RAC sh 0.5 & 110 & 7.5 \\
RAC sh 1 & 145 & 8.5 \\
RAC sh 1.5 & 165 & 9.5 \\
\hline
\end{tabular}




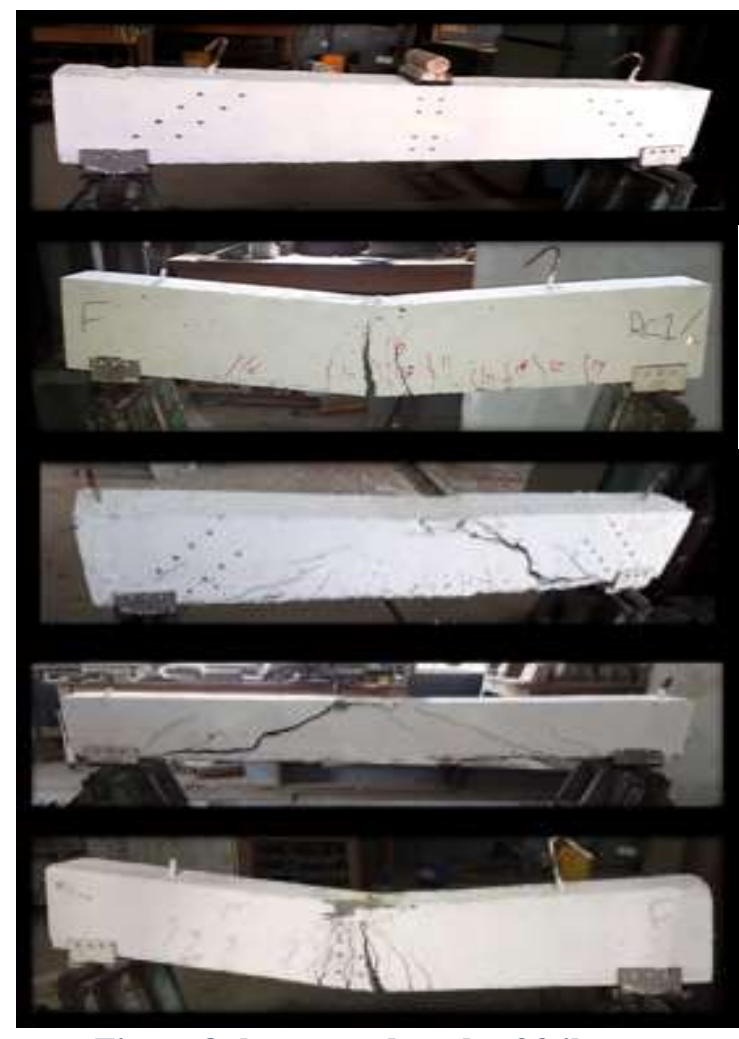

Figure 8: beams and mods of failure

Ten rectangular beam specimens were tested to assess the effects of replacing all the natural aggregates with recycled aggregates in addition to conformable 15 cubes, 45 cylinders, and 15 prisms specimens, results were explained as below:

1) Test results of mechanical properties of normal concrete replace with RA mixes decrease than NA mixes by $(20 \%, 17 \%, 18 \%$, and $9 \%)$ respectively

2) The effect of $0.5 \%$ steel fibers on mechanical properties of concrete gives larger values than the non-fibrous concrete by $(18 \%, 24 \%, 24 \%$, and $14 \%)$.

3) The effect of $1.0 \%$ steel fibers on mechanical properties of concrete gives larger values than the non-fibrous concrete by $(27 \%, 33 \%, 32 \%$, and $18 \%)$.

4) The effect of $1.5 \%$ steel fibers on mechanical properties of concrete gives larger values than the non-fibrous concrete by $(32 \%, 37 \%, 36 \%$, and $22 \%$.

5) Beams of recycled aggregate have cracking load values smaller than normal aggregate beams by $20 \%$ for Flexural behavior and by $25 \%$ for shear behaviour.

6) The cracking load (Pcr) of fibrous concrete beams greater than beams without steel fiber by (60.7-94) \% for flexural behavior and between (66-166) \% for shear behavior.
7) The beams of recycled aggregate have ultimate load values smaller than NA beams by $14 \%$ for flexural behavior and by $21 \%$ for shear behavior.

8) The ultimate load of fibrous concrete beams is greater than beams without steel fiber by (33-100) $\%$ for shear behavior.

9) The ultimate load of fibrous concrete beams is greater than beams without steel fiber by

$\%\left(T O_{-} Y\right)$ for flexure behavior.

10) The deflection of NAC beams is smaller than RAC beams for the same parameters.

11) The deflection of beams with steel fiber is smaller than the control beams (NAC) and (RAC).

\section{Conclusion}

During the review of the results of this paper and the use of recycled aggregates produced from recycled concrete and that be replaced completely with natural aggregates in the concrete mixtures, several things can be concluded:

1. A decrease in resistance in general as to compressive strength, tensile strength and modulus of rupture addition to a decrease in the elastic modulus ,therefore the Addition of different ratios of steel fiber can improve the magnitudes of this

2. Increment the vf of steel fibers due to the high tensile strength and competency of steel fibers to arrest micro-cracks and break the propagation of cracks until the composite ultimate stress of SFRC is extended .

3. The use of recycled concrete aggregate makes reduce in workability of concrete because the recycled aggregate consists of natural aggregate in addition to the old cement mortar so its effectiveness and its high ability to absorb mixture water. Therefore, the use of high water reduces materials would be useful in solving this problem .

4. During the flexural and shear test under the monotonic load, the shear failure during the review of the results of this paper and increment the vf of steel fibers due to the high tensile strength and competency of steel fibers to arrest micro-cracks and break the propagation of cracks until the composite ultimate stress of SFRC is extended .

5. The use of recycled concrete aggregate makes reduce in workability of concrete because the recycled aggregate consists of natural aggregate in addition to the old cement mortar, so its effectiveness and its occurs suddenly, while the flexural failure occurs gradually and the deflection continues for several readings after failure. 


\section{References}

[1] N. Lawson, I. Douglas, S. Garvin, C. McGrath, D. Manning, \& J. Vetterlein, "Recycling construction and demolition wastes," Environmental Management and Health, A UK perspective, Vol. 12, No.2, 146-157, 2001.

[2] Kumar, B. Sarath Chandra, Vamsi Krishna Varanasi, and P. Saha. "Sustainable development using supplementary cementitious materials and recycled aggregate," International Journal of Modern Engineering Research (IJMER) 2.1, 165-171, 2012.

[3] S.C. Nelson, "High-Strength Structural Concrete with Recycled Aggregates," University of Southern Queensland, 2004.

[4] M. Mulheron "Demolition and Reuse of Concrete and Masonry," Proc. 2nd International RILEM Symposium, products and standards in the U.K. Proc.Vol.2. Reuse of demolition waste. Japan, 1988.

[5] C. S. Poon, D .Chan, "The Use of Recycled Aggregate in Concrete in Hong Kong," Resources Conservation \& Recycling, 2006.

[6] P. Lindsell, M. Mulheron "recycling of demolition debris," A report for the Institute of Demolition Engineering, University of Oxford, Oxford UK, p, 233, 1985. 